\title{
Importance of Development of Quality Checklists
}

\author{
Eng. Shweta N. Istape ${ }^{1}$ and Prof. M. R. Apte ${ }^{2}$ \\ ${ }^{I}$ M.E Student, MIT College, Pune, India. \\ ${ }^{2}$ Guide and Professor of Civil Engg Dept,MIT College, Pune, Maharashtra, India.
}

\begin{abstract}
Supervision of a project requires a consistent, organized approach to each phase of construction, and checking the work performed against drawings, specifications, and conditions with contractors and suppliers. Quality control in construction typically involves insuring compliance with minimum standards of material and workmanship in order to insure the performance of the facility according to the design. Checking for accuracy in every job task is another part of quality control in construction.

The purpose of this paper is to provide guidance in developing quality control checklists. Checklists are generally prepared to prevent common mistakes in daily activities. Checklists are used to assure proper construction. Construction activity involves a regular sequence of operations which are needed to be checked at each level. It also provides documentations of each procedures. Visual inspections, field surveys, and laboratory testing data can be gathered using checklists. It provides an evidence, that checks has been performed by which a system can be developed to control the function of each activity.
\end{abstract}

Keywords: Audit, checklists, improvement of quality, quality assurance.

\section{Introduction}

Top quality installation work cannot be achieved without comprehensive documentation of the practicable viable and important check points at every stage of installation. It aims at creating confidence in the customer that an industry is practicing scientific and systematic mark approach in the process of assuring quality to their products.

It emphasizes the role of fact finding (not fault finding) and preventive action (not post mortem) on varied non-conformities and problems that affect the quality of construction. Checklists should provide the scope and objective of activity details, observations of non-conformance, issue of correct drawings/ specifications and availability of other technical data. In addition to this, checklists should also provide the scope of following points: if the staff is adequately trained or not for the concerning activity, has the repaired and reworked items re-inspected separately, and if special processes are under strict control, whether working instructions are implemented or not, and if the equipment's are calibrated, and also, if any balanced work remaining before starting other works, etc.

\subsection{NEED FOR STUDY}

Checklist identifies common defects and the number of observed occurrences of the defects. It is a factual tool that helps the worker to collect information regarding the defects observed.

Checklist is a tool for questioning and getting the required information to achieve the goals. Checklists are the set of documents to help the audit. Checklist fulfills the criteria for quality assurance requirements of construction activities. It checks activities to ensure compliance with the plans and specifications. It informs the contractor of any work that is in noncompliance.

Application of checklists informs the contractor of deficiencies, so that corrections can be made and retesting performed prior to covering any substandard work with additional material. Now, not only checklists helps to produce quality, defect-free work, it also helps in developing documentation of your quality practices.

\subsection{LITERATURE REVIEW}

Following points emerged from the literature review:

Department of construction and infrastructure: Northern Territory Government, Australia has indicated the following points:

It is difficult during a visit to a construction site to memorize all of the details that need to be checked and while the obvious ones stand out, many other items that should be checked are forgotten. Superintendents may get distracted or over extended due to time constraints and overlook items that may have more serious consequences later in the project. Thus Check Lists provide a guide to the inspections that are required on site for a particular project. They are a precise of the full clauses in the project specification and can be referred back to the specification if the full text of the particular item is required. The check Lists will remind you of virtually every potential problem in materials, workmanship and coordination between trades. 


\section{According to Guidelines for developing evaluation checklists: By Daniel L. Stufflebeam, Western Michigan University}

Checklists are valuable evaluation devices when carefully developed, validated, and applied. A sound evaluation checklist clarifies the criteria that at least should be considered when evaluating something in a particular area; aids the evaluator not to forget important criteria; and enhances the assessment's objectivity, credibility, and reproducibility. Moreover, such a checklist is useful in planning an enterprise, monitoring and guiding its operation, and assessing its outcomes. In the evaluation vernacular, checklists are useful for both formative and summative evaluations.

The construction of a building requires so many things in the first place, to build a substantial strong structure. It not only requires the best of the construction materials and personnel but also some of the important quality control techniques on site while at the start of the construction and in between construction.

Checklists are regularly used for inspection of construction activities. Checklists are an ongoing activity to the consultant to inspect the executed work or installations. If the work is not done as per specifications then the work is rejected and the contractor has to rework or take remedial measures, to ensure work is executed as per specifications.

Problems can be prevented using checklists by checking every stage of project from predesign to when construction begins. It reduces time needed for paperwork and saves time and money on every construction job. Checklists helps the professionals to produce the necessary documents that they need to strengthen their position in case claims are made after a job is completed. It also helps protects the users from possible by creating a protective paper trial.

Checklists are convenient and easy to use, also time saving and moneysaving. Checklists serves as a guidance for all architects, contractors, developers, and engineers involved in construction activities and they are very valuable for future reference.

\subsection{METHODOLOGY OF STUDY}

The study was carried out in two stages. In the first stage, a site visit checklist was designed; in the second, its applicability and effectiveness were tested. The applicability and effectiveness of the checklist were tested on one of the ongoing residential building project. The contractors, project managers, superintendents, supervisors, and owners of project, were all asked to use the checklist. Before the first trial, they were interviewed individually to confirm that they understood the contents and objectives of the checklist. They were also asked to report items they found to be inadequate and those that they felt to be important which were not included in the checklist. Their views were considered in preparing final format of checklist. Thereafter the contractors, supervisors, and owners of the project filled out the final checklists for daily activities.

In the second stage, the percentage of factors that conform to the requirements are determined by dividing the number of "non-conforming checks (NC)" by the "total number of checks (TC)" inspected and converting the ratio to a percentage, called as NC INDEX.

Therefore

$$
\text { NC INDEX }=\frac{\text { Total No. Of NC's (NC) }}{\text { Total No. of Checks (TC) }}
$$

Summary of details for all sections for which the distribution is:

a) Total no of checks (TC).

b) Total no of NC's (NC).

Outcome of the above is the ratio in percentage indicating 2 factors. If the NC INDEX comes within 10\% then green token is issued for that activity and if the index is above $10 \%$ then red token is issued.

\section{Checklist Design}

The checklist is divided into four components: Equipments \& tools, checks - before work, during work and after work. Checklist items were designed to address important work and defects based on current site visit deficiencies. It also considers frequently occurring defects, and development of the construction productivity factors based on the system and also out of the checks carried as per classification indicated above. 


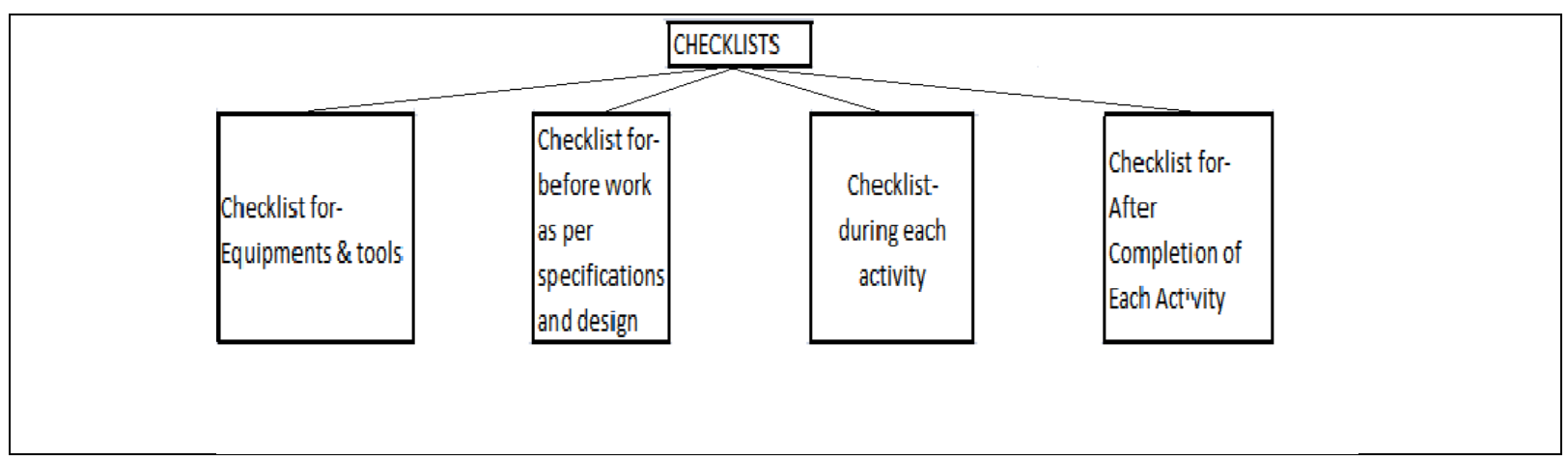

Fig: 1 Framework for checklist design

Every item was again analyzed as under:

a) Number of equipment's, capacity and supporting tools such as trowel, tray for mortar mixing, line-dori, etc.

b) Manpower- operators, helpers with experience.

c) Checking for cleaning of area for removal of foreign material, water tightness, repairing identified defects and damages.

d) After completion of activity-checking for leakage, slopes and any other defects.

Checklist provides a measurement of workmanship of a constructed product and respective use of processes. Development of a complete checklist is dependent on selecting important factors from drawings, specifications, standards, tolerances, and also manufacturing standards.

\subsection{CASE STUDY}

One construction site is selected for the study where the activities can be regularly monitored. The construction site named PITTIE KOURTYARD at Kharadi, Pune-Nagar Road, Pune - 46. It complies with three towers of G+20 floors. Client's name is "RAJA BAHADUR INTERNATIONAL LTD". and quality consultant were "Construction Quality Rating Agency Pvt. Ltd. (CQRA)" and with this, material testing and controlling has been carried out by M/S Durocrete.

Name of the Project : "Construction of Residential High Rise Towers.

Client : Raja Bahadur International Limited.

Quality Consultant: CQRA

Architect: Rajeev Sathe

Contractor: For RCC works, Sai Deep Enterprises- A\&C BLDG

Mr. Takwale-B BLDG

Type of Contract: Item rate contract.

Present Status of Project: For RCC work completion of Buildings is as follows

A- $45 \% \quad$ B- $-40 \% \quad$ C- $-35 \%$

Location of the Site: Site is located near Pune Airport, Kharadi, Maharashtra, India.

Advanced technical features provided in the above project are:

* Gas Leak Detector \& Controller

* Environment friendly green building registered with IGBC.

* Vastu principles incorporated.

* Earthquake resistant RCC frame structure.

* 3 high speed elevators including 1 stretcher lift

* Vehicle free garden podium

* Eco friendly waste management system and sewage treatment plant.

A typical checklist for "waterproofing work for toilet" was prepared and the checks been performed for the above building by me are given below. The following checklist provides a list of all issues that need to be considered as part of the evaluation of the project. The complete work breakdown of waterproofing is as given in table 1 below.

\section{Inspection methodology for quality assurance:}

1. Check whether method of waterproofing is as recommended by consultant and if proper application methods are used.

2. Check whether all the drawings with relevant details for water proofing treatment are available with the site staff.

3. The detailed instructions of waterproofing should bear the signature of the consultant's. 
4. PVC water stoppers must be provided at the junction of all joints in the water retaining structures like tanks, swimming pools etc.

5. The waterproofing supervision job card should be attached.

TABLE: 1 CHECKLIST FOR WATERPROOFING OF TOILETS

\begin{tabular}{|c|c|c|c|}
\hline \multirow[b]{4}{*}{ NO } & CHECKLIST FOR WATER PROOFING OF TOILETS & \multirow[b]{2}{*}{ DATE: } & \multirow[b]{2}{*}{ 14/10/2013 } \\
\hline & DESCRIPTION :Water proofing & & \\
\hline & LOCATION: Bldg-B, Flat no-202, Master bed toilet & TIME: & 4:05 PM \\
\hline & EQUIPMENT AND TOOLS & CHECKED & REMARK \\
\hline 1 & Necessary tools available with masons & $\square$ & \\
\hline 2 & Grouting pump available on site & $\mathbf{x}$ & \\
\hline 3 & MS tray/Sunk/Brick bund used for mixing mortar & $\square$ & \\
\hline \multirow[t]{2}{*}{ TOTAL } & & $2 \square, \mathbf{X}$ & \\
\hline & PROCEDURES BEFORE WATER PROOFING OF TOILET & & \\
\hline 1 & Cleaning of sunk slab surface done & $\square$ & \\
\hline 2 & Injection grouting done as specified & $\mathbf{x}$ & \\
\hline 3 & Injection grouting done till no leakages observed & $\mathbf{x}$ & \\
\hline \multirow[t]{2}{*}{ TOTAL } & & $\mathbf{1} \square, \mathbf{2 X}$ & \\
\hline & DURING WORK & & \\
\hline 1 & Thickness, mix proportion for mortar, slope in base coat if proper & $\square$ & \\
\hline 2 & Height of base coat as specified & $\square$ & \\
\hline 3 & Drain spout fixed within base coat as specified & $\square$ & \\
\hline 4 & Base coat cured for 3 days by ponding & $\square$ & \\
\hline 5 & PVC outlet pipe roughened before fixing in hole & $\square$ & \\
\hline 6 & Drain pipes erected over base coat & $\square$ & \\
\hline 7 & Brick bats soked for minimum 15 min before use & $\square$ & \\
\hline 8 & Proportion for mortar IN BBC as specified & $\square$ & \\
\hline 9 & BBC layed with proper slope using line dori /intermediate thiyyas & $\square$ & \\
\hline 10 & $\mathrm{BBC}$ cured for 3 days & $\square$ & \\
\hline 11 & Thiyyas of final coat proper (slope checked) & $\square$ & \\
\hline 12 & Top coat and finishing coat applied as specified & $\square$ & \\
\hline \multirow[t]{2}{*}{ TOTAL } & & $12 \square$ & \\
\hline & AFTER WORK & & \\
\hline 1 & Date of application of finishing coat displayed for monitoring curing & $\square$ & \\
\hline 2 & Finishing coat cured for 7 days & $\square$ & \\
\hline 3 & Offset of finishing coat with respect to slab kept proper & $\mathbf{X}$ & \\
\hline TOTAL & & $2 \square, \mathbf{1 X}$ & \\
\hline \multirow[t]{3}{*}{$\begin{array}{l}\text { GRAND } \\
\text { TOTAL }\end{array}$} & & $17 \square, 4 X$ & \\
\hline & CHECKED ALL ABOVE AND READY FOR INSPECTION: & $\begin{array}{l}\text { CHECKED } \\
\text { BY }\end{array}$ & SHWETA \\
\hline & ALL INSPECTION CARRIED OUT AS PER REMARKS: & $\begin{array}{l}\text { APPROVED } \\
\text { BY }\end{array}$ & \\
\hline
\end{tabular}

Total No. of Checks = 21,

Total No. of NC's $=4$

Observed point- If in any case honeycombing is observed, then grouting pump should be available on site.

NOTE: $\sqrt{ }$ or $\mathrm{P}=$ Pass= checks are SATISFACTORY ARE CALLED "yes"

$\mathrm{X}$ or $\mathrm{F}=$ Fail $=$ checks are not SATISFACTORY

NC INDEX $=\frac{\text { Total No.of NCs }(\text { NC) }}{\text { Total No.of Checks }(\text { TC) }}=$ For e.g. $4 / 21=0.190=19 \%$

Which is severe i.e. more than $10 \%$ so Red Token is issued.

Issue of such red alert is given to concern person when some serious quality related problem is observed on site. And also time period is given in order to rectify the activities related to NC with urgent attention and intervention. It is also recommended that after given period a fresh checklist is required to be filled in order to 
check improvement in NC INDEX which is expected to fall below 10\%.With the help of different types of checklists, NC Index are calculated monthly, which in turn shows us the quality assurance parameter.

In order to describe the NC status for a month of October 2013, data is collected and which is as given below:

TABLE: 2 DATA FOR MONTH OF OCTOBER 2013

\begin{tabular}{|c|c|c|c|c|c|}
\hline SR. NO & $\begin{array}{l}\text { DATES OF } \\
\text { OCTOBER }\end{array}$ & CONFORMITIES & $\begin{array}{c}\text { NON } \\
\text { CONFORMITIES } \\
\end{array}$ & $\begin{array}{c}\text { TOTAL } \\
\text { CHECKS } \\
\end{array}$ & $\begin{array}{c}\text { NC } \\
\text { INDEX }(\%) \\
\end{array}$ \\
\hline 1 & $01 / 10 / 2013$ & 19 & 2 & 21 & 9.52381 \\
\hline 2 & $02 / 10 / 2013$ & 18 & 3 & 21 & 14.28571 \\
\hline 3 & 03/10/2013 & 16 & 5 & 21 & 23.80952 \\
\hline 4 & $04 / 10 / 2013$ & 15 & 6 & 21 & 28.57143 \\
\hline 5 & $05 / 10 / 2013$ & 17 & 4 & 21 & 19.04762 \\
\hline 6 & $07 / 10 / 2013$ & 18 & 3 & 21 & 14.28571 \\
\hline 7 & 08/10/2013 & 19 & 2 & 21 & 9.52381 \\
\hline 8 & $09 / 10 / 2013$ & 16 & 5 & 21 & 23.80952 \\
\hline 9 & $10 / 10 / 2013$ & 14 & 7 & 21 & 33.33333 \\
\hline 10 & $11 / 10 / 2013$ & 18 & 3 & 21 & 14.28571 \\
\hline 11 & $12 / 10 / 2013$ & 15 & 6 & 21 & 28.57143 \\
\hline 12 & $14 / 10 / 2013$ & 17 & 4 & 21 & 19.04762 \\
\hline 13 & $15 / 10 / 2013$ & 19 & 2 & 21 & 9.52381 \\
\hline 14 & $16 / 10 / 2013$ & 15 & 6 & 21 & 28.57143 \\
\hline 15 & $17 / 10 / 2013$ & 17 & 4 & 21 & 19.04762 \\
\hline 16 & $18 / 10 / 2013$ & 18 & 3 & 21 & 14.28571 \\
\hline 17 & $19 / 10 / 2013$ & 19 & 2 & 21 & 9.52381 \\
\hline 18 & $21 / 10 / 2013$ & 20 & 1 & 21 & 4.761905 \\
\hline 19 & $22 / 10 / 2013$ & 19 & 2 & 21 & 9.52381 \\
\hline 20 & $23 / 10 / 2013$ & 19 & 2 & 21 & 9.52381 \\
\hline 21 & $24 / 10 / 2013$ & 18 & 3 & 21 & 14.28571 \\
\hline 22 & $25 / 10 / 2013$ & 20 & 1 & 21 & 4.761905 \\
\hline 23 & $26 / 10 / 2013$ & 18 & 3 & 21 & 14.28571 \\
\hline 24 & $28 / 10 / 2013$ & 19 & 2 & 21 & 9.52381 \\
\hline 25 & $29 / 10 / 2013$ & 18 & 3 & 21 & 14.28571 \\
\hline 26 & $30 / 10 / 2013$ & 18 & 3 & 21 & 14.28571 \\
\hline 27 & $31 / 10 / 2013$ & 20 & 1 & 21 & 4.761905 \\
\hline
\end{tabular}

The graph showing deviations of total number of checks, conformities and non conformities based on above data is given in fig. 2 below:

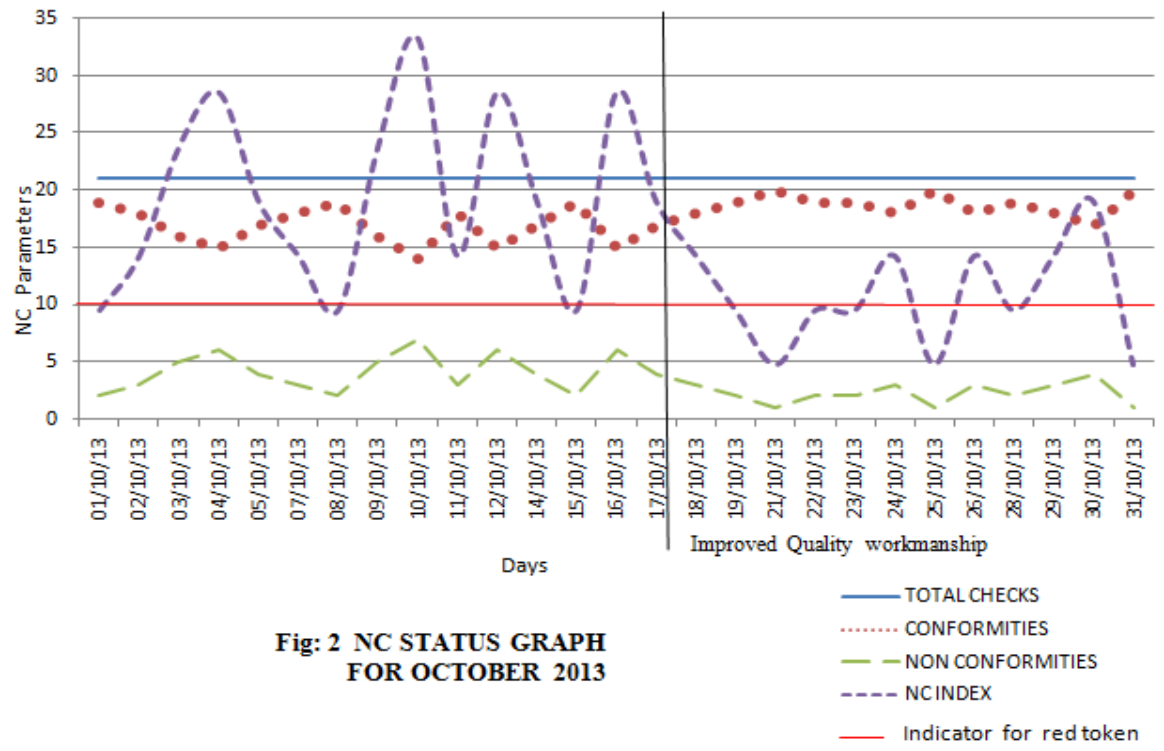




\subsection{ANALYSIS AND CONCLUSION}

From the above graph we can see that the NC Indices are fluctuating rapidly in the beginning of month. As the work progresses the percentage of NC Index has fallen in 7 cases and which is below 10\%. This indicates number of conformities has increased and as a result the improvement of quality is observed. Similar data over a period of six months can show substantial improvement in quality of work as NC Index would fall below $10 \%$. Like this, analysis on NC INDICES is carried out in the subsequent months and summary of same for the entire work is reviewed and presented to respective authorities such as client, contractor etc. with instructions to take suitable corrections on the particular activity. From the total numbers of NC INDICES we can verify whether quality of work is really improved or still rectification is required to be done. This reflects the improvement of quality of workmanship at the site which can easily be assessed and understood by the clients. Thus keeping in view the above detail study of various items on a project site, the progressive improvement graphs showing tendency to increase in number of NC INDICES less than $10 \%$ will be worked out to confirm the system mentioned in this paper being implemented successfully and this will be done in subsequent project work on this topic.

\subsection{RECOMMENDATIONS}

Checklists is a tool of quality assessment and indicates total NC indices. These NC indices should get reduced as any project work progresses. NC index less than 10\% indicates GOOD QUALITY workmanship and such quality should be regularly implemented at large projects by engineers, contractors, clients etc.

Application of checklist should be done regularly for quality inspection, for recording specific quality data of material and constructed work, when a site work is lacking from standardized practices. The checklists could be used on other projects that exhibit more complications such as huge infrastructure projects. Same work can be improved by developing and using different software's by which quality can be easily controlled on multiple activities. Considering this approach further study will be carried out by using application of different software's in subsequent project work.

\section{Acknowledgements:}

I am thankful to CQRA members, for allowing me to work on this innovative concept of carrying out checks on the work done on site to maintain good quality control.

\section{References}

[1]. By Andrew S. Chang1; Sin-Jing Du2; and Fang-Ying Shen3, Engineer Self-Evaluation Checklist for Effective Site Visits, Journal of Construction Engineering and Management.

[2]. By Daniel L. Stufflebeam, July 2000, Guidelines for developing evaluation checklist. 